\title{
RESEARCH
}

Open Access

\section{Vagal-a7nAChR signaling promotes lung stem cells regeneration via fibroblast growth factor 10 during lung injury repair}

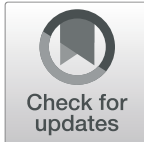

Xiaoyan Chen ${ }^{1 \dagger}$, Caiqi Zhao ${ }^{2 \dagger}$, Cuiping Zhang ${ }^{1 \dagger}$, Qingmei $\mathrm{Li}^{2}$, Jie Chen², Lianping Cheng ${ }^{2}$, Jian Zhou', Xiao $\mathrm{Su}^{2^{*}}$ and Yuanlin Song ${ }^{1,3,4^{*}}$

\begin{abstract}
Background: Proliferation and transdifferentiation of lung stem cells (LSCs) could promote lung injury repair. The distal airways of the lung are innervated by the vagus nerve. Vagal-alpha7 nicotinic acetylcholine receptor (a7nAChR) signaling plays a key role in regulating lung infection and inflammation; however, whether this pathway could regulate LSCs remains unknown.

Methods: $\mathrm{LSCs}\left(\mathrm{Sca} 1^{+} \mathrm{CD} 45^{-} \mathrm{CD} 31^{-}\right.$cells) were isolated and characterized according to a previously published protocol. a7nAChR knockout mice and wild-type littermates were intratracheally challenged with lipopolysaccharide (LPS) to induce lung injury. A cervical vagotomy was performed to study the regulatory effect of the vagus nerve on LSCs-mediated lung repair. a7nAChR agonist or fibroblast growth factor 10 (FGF10) was intratracheally delivered to mice. A single-cell suspension of lung cells was analyzed by flow cytometry. Lung tissues were collected for histology, quantitative real-time polymerase chain reaction (RT-PCR), and immunohistochemistry.

Results: We found that LSCS maintained multilineage differentiation ability and transdifferentiated into alveolar epithelial type II cells (AEC2) following FGF10 stimulation in vitro. Vagotomy or a7nAChR deficiency reduced lung Ki67 $7^{+}$LSCs expansion and hampered the resolution of LPS-induced lung injury. Vagotomy or a7nAChR deficiency decreased lung FGF10 expression and the number of AEC2. The a7nAChR agonist-GTS-21 reversed the reduction of FGF10 expression in the lungs, as well as the number of Ki67 ${ }^{+}$cells, LSCs, Ki67 ${ }^{+} \mathrm{LSCs}$, and AEC2 in LPS-challenged vagotomized mice. Supplementation with FGF10 counteracted the loss of Ki67 ${ }^{+} \mathrm{LSCs}$ and AEC2 in LPS-challenged a7nAChR knockout mice.
\end{abstract}

Conclusions: The vagus nerve deploys a7nAChR to enhance LSCs proliferation and transdifferentiation and promote lung repair in an FGF10-dependent manner during LPS-induced lung injury.

Keywords: Vagus nerve, Lung stem cells (LSCS), Multipotential differentiation, Proliferation

\footnotetext{
* Correspondence: xsu@ips.ac.cn; song.yuanlin@zs-hospital.sh.cn

${ }^{+}$Xiaoyan Chen, Caiqi Zhao and Cuiping Zhang contributed equally to this work.

2Unit of Respiratory Infection and Immunity, Institut Pasteur of Shanghai, Chinese Academy of Sciences, 320 Yueyang Road, Shanghai 200031, People's Republic of China

'Department of Pulmonary and Critical Care Medicine, Zhongshan Hospital, Fudan University and Shanghai Respiratory Research Institute, 180 Fenglin Road, Shanghai 200032, People's Republic of China

Full list of author information is available at the end of the article
}

(c) The Author(s). 2020 Open Access This article is licensed under a Creative Commons Attribution 4.0 International License, which permits use, sharing, adaptation, distribution and reproduction in any medium or format, as long as you give appropriate credit to the original author(s) and the source, provide a link to the Creative Commons licence, and indicate if changes were made. The images or other third party material in this article are included in the article's Creative Commons licence, unless indicated otherwise in a credit line to the material. If material is not included in the article's Creative Commons licence and your intended use is not permitted by statutory regulation or exceeds the permitted use, you will need to obtain permission directly from the copyright holder. To view a copy of this licence, visit http://creativecommons.org/licenses/by/4.0/ The Creative Commons Public Domain Dedication waiver (http://creativecommons.org/publicdomain/zero/1.0/) applies to the data made available in this article, unless otherwise stated in a credit line to the data. 


\section{Background}

Evidence indicates that lung resident stem cells possess a proliferative capacity in vivo, and they are activated and subsequently proliferate and differentiate into lung epithelium to effectively regenerate and repair an injured lung [1-3]. Failure to regenerate the lung epithelium contributes to poor resolution in lung diseases such as pneumonia and acute respiratory distress syndrome (ARDS), and it leads to pulmonary scarring and fibrosis [4]. Thus, the reparative capacity of lung stem cells has attracted considerable research attention in terms of both elucidating the mechanism underlying regeneration after lung injury and developing therapeutic strategies for treating injured lungs.

In the adult mouse lung, the stem cell marker (Sca1) has previously been identified as a vital marker for the isolation of candidate nonendothelial $\left(\mathrm{CD} 31^{-}\right)$, nonhematopoietic $\left(\mathrm{CD} 45^{-}\right)$bronchioalveolar stem cells (BASCs) located at the bronchioalveolar duct junction that can selfrenew over multiple passages and differentiate into airway and alveolar epithelium [1]. However, McQualter et al. reported that lung fibroblastic progenitor cells are highly enriched in the $\mathrm{Sca} 1^{+} \mathrm{CD} 45^{-} \mathrm{CD} 31^{-}$population of cells [5]. Hegab et al. revealed that lung resident $\mathrm{Sca} 1^{+} \mathrm{CD} 45^{-} \mathrm{CD} 31^{-}$ cells exhibited extensive self-renewal capacity and can differentiate into lung epithelial cells (alveolar epithelial type I cells: AEC1, type II cells: AEC2, and club cells) and endothelial cells, and they even exhibited some mesenchymal ability [6]. Although there is divergence regarding their differentiation capacity, lung resident $\mathrm{Sca}^{+} \mathrm{CD} 45^{-} \mathrm{CD} 31^{-}$ cells have been consistently found to have stem cell properties and contribute to lung regeneration [1, 5-7].

During regeneration processes, the lung stem cell niche plays a key role in initiating and coordinating selfrenewal and terminal differentiation. Signals involved in the cross-talk between LSCs and the microenvironmental niche include paracrine fibroblast growth factors (FGFs), which regulate cell proliferation, differentiation, motility, and survival. In particular, FGF10, which is expressed in the adjacent distal lung mesenchyme, binds to and activates fibroblast growth factor receptor 2 (FGFR2) on epithelial progenitors to direct distal lung development, including branching morphogenesis and regeneration after damage [8-12]. FGF10 signaling could be reactivated in the adult lung after injury to regenerate the epithelium $[2,11]$. The exact signal triggering the FGF10 network in the context of lung repair after LPS induced injury, however, is not well understood.

The vagal nerve, the main dominant nerve of the distal airway of the lung, which contains alveoli [13, 14], is known to be regulators of both respiratory clocks [15] and local lung immunity [16]. Our group [13, 17, 18] and other groups [19-23] have reported that vagotomy or deletion of alpha 7 nicotinic acetylcholine receptor $(\alpha 7 \mathrm{nAChR})$, the receptor for a vagal neurotransmitter, significantly amplifies inflammatory responses and exacerbates tissue damage that occurs during infection, endotoxemia, and radiation-induced lung injury. In addition, several studies have suggested that vagal signals are involved in the proliferation, differentiation, and function of various stem cells [24-27]. However, whether they regulate lung resident stem cells during the reparative phase of lung injury has not been clarified. In this study, we investigated whether and how vagal$\alpha 7 \mathrm{nAChR}$ signaling regulates LSCs to participate in the reparative process of lung injury.

\section{Methods}

\section{Chemicals}

Lipopolysaccharides (LPS) were obtained from Pseudomonas aeruginosa (L9143). Dispase II, collagenase IA, deoxyribonuclease I, penicillin/streptomycin/amphotericin B, and insulin/transferrin/selenium were purchased from Sigma-Aldrich (St Louis, MO, USA). GTS-21 dihydrochloride (DMBX-A) (ab120560), a specific $\alpha 7 n A C h R$ agonist, was purchased from Abcam (Cambridge, MA, USA). FGF10 was provided by Newsummit, Shanghai, China. Anti-mouse CD16/CD32 and phycoerythrin (PE) rat anti-mouse/human CD44 monoclonal antibodies (IM7) were purchased from eBioscience (San Diego, CA, USA). Fixable viability stain 780 (FVS780), allophycocyanin (APC) rat anti-mouse CD45 (clone 30-F11), APC rat anti-mouse CD31 (clone MEC 13.3), and PE rat antimouse Ly-6A/E (clone D7) were obtained from BD Biosciences (San Jose, CA, USA). PE/Cyanine 7 Armenian hamster anti-mouse/rat (clone HM $\beta 1-1)$ CD29, PE rat anti-mouse CD105 (clone MJ7/18), and fluorescein isothiocyanate (FITC) anti-mouse TER-119/erythroid cells (clone TER-119) were obtained from Biolegend (San Diego, CA, USA). A rabbit anti-FGFR2 antibody was purchased from Abcam (Cambridge, MA, USA).

\section{Animals}

$\alpha 7 \mathrm{nAChR}$ knockout mice $\left(\alpha 7 \mathrm{nAChR}^{-/-}\right.$, background, C57BL/6J, B6.129S7-Chrna7tm1Bay/J, stock no. 003232) were purchased from Jackson Laboratory (Bar Harbor, ME, USA) [13]. Littermate wild-type mice $\left(\alpha 7 \mathrm{nAChR}^{+/+}\right.$, background, C57BL/6J, 6-8 weeks old) were used as controls. The mice were housed with free access to food and water in 12-h dark/light cycles. Anesthetization was induced by intraperitoneal injection of pentobarbital sodium $(80 \mathrm{mg} / \mathrm{kg})$. Subsequently, FGF10 (5 mg/kg) dissolved in phosphate-buffered saline (PBS) or PBS with equal volume was intratracheally delivered. Three days later, mice were intratracheally injected with $2.5 \mathrm{mg} / \mathrm{kg}$ of LPS dissolved in PBS. Mice were humanely sacrificed by lethal overdose of pentobarbital sodium on the 7 th day. Animal experiments were approved by the Committees 
on Animal Research of the Institut Pasteur of Shanghai, Chinese Academy of Sciences, China. The protocols were performed in accordance with the United States National Institutes of Health Guide for the Care and Use of Laboratory Animals (8th Edition, 2011).

\section{Unilateral vagotomy}

Cervical vagotomies were performed as described previously [28]. Briefly, a longitudinal midline incision was made in the ventral region of the neck before blunt dissection. The overlying muscles and fascia were separated until the right vagus was visible. For the vagotomy $(\mathrm{Vx})$ group, the vagus was carefully stripped away from the carotid artery and was carefully cut. For the sham group, the vagus was kept intact. The wound was closed and sutured.

\section{Animal treatments}

After undergoing vagotomy, mice were intratracheally injected with either the indicated concentration (2.5 or $5 \mathrm{mg} / \mathrm{kg}$ ) of LPS dissolved in PBS or an equal volume of PBS. Subsequently, GTS-21 (4 mg/kg), FGF10 (5 mg/kg), or PBS was intratracheally delivered.

\section{Histological analysis}

Mouse lung sections were stained with hematoxylineosin to determine the extent of injury. The lung injury was graded in a blinded manner as described previously [29]: $0=$ no injury; $1=$ area of lung injury less than $25 \%$; $2=$ area of lung injury between 25 and 50\%; $3=$ area of lung injury between 50 and 75\%; and $4=$ area of lung injury more than $75 \%$. Immunohistochemistry was performed with an anti-prosurfactant protein $\mathrm{C}$ (proSP-C) antibody (MeckMillipore, Darmstadt, Germany) or an anti-FGF10 antibody (ABclonal, Boston, USA). Sections were covered with a DAB tetrahydroxychloride solution and then were counterstained with hematoxylin. The numbers of SP-C-positive cells were counted in 6 random fields $(\times 200)$, and the results were expressed as the average number of SP-C-positive cells/lung nucleated cells from 3 or more animals in each group. Scoring of FGF10 protein expression was determined by the hybrid scoring system (H-score) [30]. The intensity of the staining was classified into 4 grades: 0 , no staining; 1 , weak staining; 2, moderate staining; and 3, strong staining, and then score was multiplied by the percent of positive cells in the area. All the scores were performed in a blinded manner.

\section{Flow cytometry}

After preincubating for $15 \mathrm{~min}$ with anti-mouse CD16/ 32 antibodies, lung cells were labeled with primary or isotype control antibodies. Isotype antibodies and unstained controls were set to demonstrate specificity of staining and to establish the criteria for target populations (for simplicity, data were not shown regarding these controls). Debris and aggregates were excluded, and live cells were analyzed by LSRFortessa (BD Biosciences, San Jose, CA, USA). Data were analyzed by FlowJo vX.0.7 software (Tree Star Inc., Ashland, OR, USA).

\section{Isolation of lung stem cells}

Single-cell suspensions of lung tissue were prepared for each experiment using 3-5 mice as described [5] with modification. In brief, $1 \mathrm{ml}$ of dispase $(2 \mathrm{U} / \mathrm{ml})$ was injected through the trachea. Subsequently, the trachea was removed, and the lungs were minced and incubated in a $37^{\circ} \mathrm{C}$ shaking incubator for $45 \mathrm{~min}$ in $2 \mathrm{ml}$ of $2 \mu \mathrm{g} / \mathrm{ml}$ collagenase/dispase containing $0.001 \%$ DNAse. These lung suspensions were filtered through $40-\mu \mathrm{m}$ cell strainers, centrifuged, and depleted of red blood cells using RBC lysis buffer. Subsequently, Sca $1^{+} \mathrm{CD} 45^{-} \mathrm{CD} 31^{-}$cells were sorted using MoFlo Astrios (USA).

\section{Cell culture}

Sorted cells were resuspended at a concentration of $1 \times$ $10^{6}$ cells $/ \mathrm{ml}$ in DMEM/F12 supplemented with Lglutamine/pyruvate (Invitrogen), $0.5 \%$ or $10 \%$ fetal bovine serum (FBS) (Gibco, USA), penicillin/streptomycin/ amphotericin B, and insulin/transferrin/selenium. Differentiation experiments were carried out using "mesenchymal stem cell functional identification kit" (Cyagen Biosciences Inc., Santa Club, CA, USA) according to the manufacturer's protocols.

\section{Quantitative real-time polymerase chain reaction}

Total RNA was extracted from cells or homogenized lungs using TRIzol reagent (Invitrogen, CA, USA) according to the manufacturer's instructions. RNA was reversetranscribed to generate cDNA using a reverse transcriptase kit (Toyobo, Tokyo, Japan), which was followed by quantitative real-time polymerase chain reaction (RT-PCR) analysis (Toyobo, Tokyo, Japan). The primers were as follows: SP-C: 5'-GGAGCACCGGAAACTCAGAA-3' (forward), 5'-CTGGCTTATAGGCCGTCAGG-3' (reverse); club-cell specific protein (CCSP): 5'-ATGAAGATCGCCATCACA ATCAC-3' (forward); 5'-GGATGCCACATAACCAGA CTCT-3' (reverse); FGF10: 5'-TTTGGTGTCTTCGT TCCCTGT-3' (forward); 5'-TAGCTCCGCACATG CCTTC-3' (reverse); Ki67: 5'-ATCATTGACCGCTC CTTTAGGT-3' (forward); 5'-GCTCGCCTTGATGG TTCCT-3' (reverse); 18s: 5'-CGGCTACCACATCCAAGGAA-3' (forward); and 5'CCTGTATTGTTATTTTTCGTCACTACCT-3' (reverse). The relative expression levels of genes were determined by the $2^{-\Delta \Delta C T}$ method [31] and were normalized to 18s. 


\section{Immunofluorescence staining}

Cells were seeded on cell culture chamber slides (NEST, San Diego, CA, USA) and allowed to adhere overnight. They were fixed with $4 \%$ paraformaldehyde and then were incubated in 5\% BSA and $0.1 \%$ Triton X-100 to block nonspecific binding and permeabilize the cell membrane, respectively. Slides were mounted with fluoroshield mounting medium containing DAPI (Abcam, Cambridge, MA, USA) and were viewed on a confocal microscope (FV3000, Olympus, Tokyo, Japan). An antimouse pro-SP-C antibody was purchased from Proteintech. An anti-Ki-67-eFluor 570 antibody was obtained from eBioscience (San Diego, CA, USA). An anti-alpha smooth muscle actin ( $\alpha$-SMA) antibody was acquired from Cell Signaling Technology (Danvers, MA, USA), and an anti-CCSP antibody was acquired from Abcam (Cambridge, MA). Anti-aquaporin-5 (AQP5), CD31, and $\alpha 7 \mathrm{nAChR}$ antibodies were obtained from Santa Cruz Biotechnology (Santa Cruz, CA). The secondary antibodies were FITC- and cyanine 3 (Cy3)-conjugated antibodies. All staining procedures were performed with appropriate isotype controls.

\section{Statistical analysis}

Statistical analysis was performed with GraphPad Prism 6 software (GraphPad, San Diego, CA, USA). Student's $t$ tests were utilized unless there were multiple comparisons, in which cases one-way analysis of variance (ANOVA) with Turkey's correction for post hoc paired comparisons was adopted. All analyses were two sided. The significance level was set at $p<0.05$. The results are shown as the mean \pm standard deviation (SD).

\section{Results}

\section{LSCs possess multilineage differentiation ability and} transdifferentiate into AEC2 under FGF10 stimulation LSCs (positive for Scal and negative for CD45 and CD31) were sorted utilizing the sorting strategy that is shown in Fig. 1a, and then, they were seeded into culture plates. We found that LSCs demonstrated trilineage differentiation abilities: osteogenesis (Fig. 1b (i)), chondrogenesis (Fig. 1b (ii)), and adipogenesis (Fig. 1b (iii)). LSCs also possessed features of mesenchymal stem cells: positive for CD29, CD44, CD105, and Sca1 and negative for CD45, CD31, Ter119, and Flk1 (Fig. 1c). Through limiting dilution analysis, we found that LSCs had selfrenewal capacity (Suppl. 1A). These results were consistent with previous investigations [6]. In addition, LSCs expressed FGFR2 (Fig. 1d), the main receptor for FGF10. When treated with FGF10, LSCs elongated and aligned themselves end to end in alveolar-like shapes (Suppl. 1B). We used Ki67 as a cell proliferation marker, since it is present throughout the active phases of the cell cycle (G1, $\mathrm{S}, \mathrm{G} 2$, and mitosis) but is absent from resting cells (G0)
[32]. FGF10 increased the number of AEC2 (labeled by $\mathrm{SP}-\mathrm{C}$ ) and $\mathrm{Ki}^{+} 7^{+}$cells but not club cells (marked by CCSP) or AEC1 (marked by AQP5, Fig. 1e-h). The results indicated that LSCs maintained selfrenewal capacity and possessed multilineage differentiation ability. FGF10 plays a vital role in mediating LSCs proliferation and transdifferentiation.

\section{Vagus nerve does not influence the decrease in viability and proliferation of LSCs at the early phase (acute inflammation) of LPS-induced lung injury}

We utilized an LPS-induced lung injury model to investigate the impact of the vagal nerve on LSCs. Mice were vagotomized 5 days before LPS challenge, as shown in Fig. 2a and b. Using the gating strategy shown in Fig. 2c, we found that there were decreased numbers of LSCs (Fig. 2d), Ki67 ${ }^{+}$LSCs (Fig. 2e), and Ki67 ${ }^{+}$cells (Fig. 2f) and a negative impact on viability (Fig. $2 \mathrm{~g}$ ) on the 1st day after LPS ( $5 \mathrm{mg} / \mathrm{kg}$ ) challenge. Furthermore, LSCs (Fig. 2h), proliferative LSCs (Fig. 2i), and Ki67 ${ }^{+}$cells (Fig. 2j) were decreased on the 3rd day after LPS $(5 \mathrm{mg} / \mathrm{kg}$ ) challenge, but there was no decrease in cell viability of LSCs (Fig. 2k). These results indicated that LPS could cause loss of LSCs by inhibiting their proliferation at the acute phase of lung injury. However, the worsening effect of a vagotomy was not observed at the early phase of LPS $(5 \mathrm{mg} / \mathrm{kg})$-induced lung injury.

\section{a7nAChR activation accelerates LSCs expansion and the reparative process at the late phase of LPS-induced lung injury}

We proposed that the effect of vagal- $\alpha 7 n A C h R$ signaling on LSCs may be exerted at the late phase of LPSinduced lung injury. Because when using a dose of $5 \mathrm{mg} /$ $\mathrm{kg}$ LPS to challenge mice, the Vx + LPS group showed high mortality after the 3rd day, we used a dose of 2.5 $\mathrm{mg} / \mathrm{kg}$ LPS in the following experiments (Fig. 3a). Importantly, we observed that GTS-21 ( $\alpha 7 n$ AChR agonist) led to the expansion of LSCs and Ki67 ${ }^{+}$LSCs. GTS-21 treatment advanced the recovery time of LSCs from the 14th day to the 7th day after ALI (Fig. 3b) and led to a significantly increased number of $\mathrm{Ki} 67^{+} \mathrm{LSCs}$ on the 14th day and a slightly increased number of $\mathrm{Ki} 67^{+}$LSCs on the 7th day (Fig. 3c). Moreover, the degree of pathological injury appeared different in GTS-21-treated mice at later times of ALI, particularly day 3 , where there was reduced exudation, decreased epithelial thickness, and a reduction in the number of inflammatory cells (Fig. 3d, e). This implied that $\alpha 7 \mathrm{nAChR}$ activation drove LSCs to proliferate and replenish their population and that they may also transdifferentiate into new alveolar epithelial cells for a long period after lung injury. 


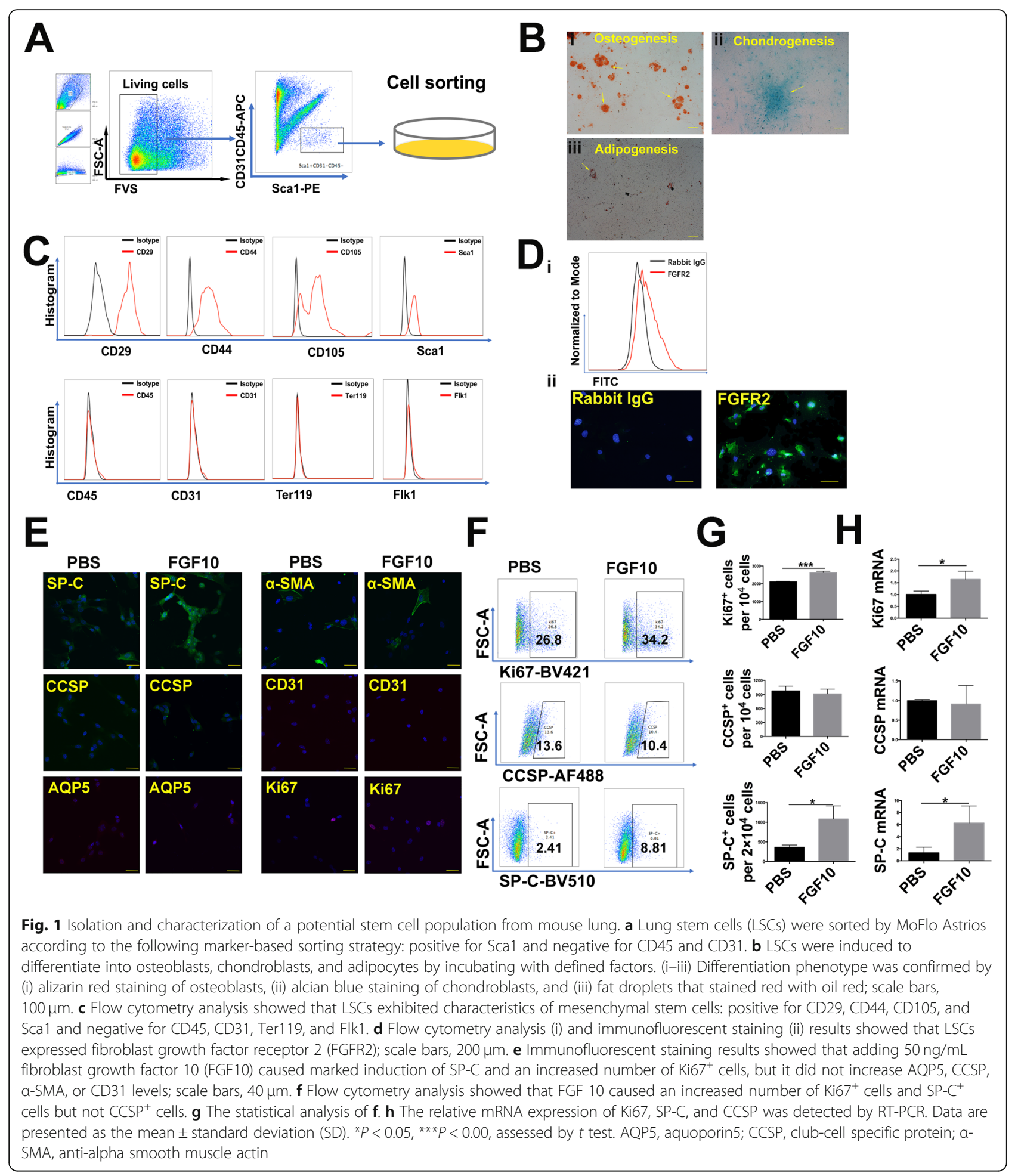

The vagus nerve via $a 7 n A C h R$ promotes LSCs proliferation and transdifferentiation at the late (reparative) phase of LPS-induced lung injury

We found that vagotomy increased mortality in LPSchallenged mice, which was rescued by administration of GTS-21 (Fig. 4a). In addition, vagotomy significantly decreased body weight by approximately $13.3 \%$ on the 12th day, delayed body weight recovery (Fig. 4b), and exacerbated lung pathological damage in LPS-induced lung injury on the 7th day (Fig. 4c, d). GTS-21 reversed vagotomyinduced body weight loss and lung injury (Fig. 4b-d). Moreover, vagotomy led to $\mathrm{Ki}^{+} 7^{+}$cells and LSCs loss and 


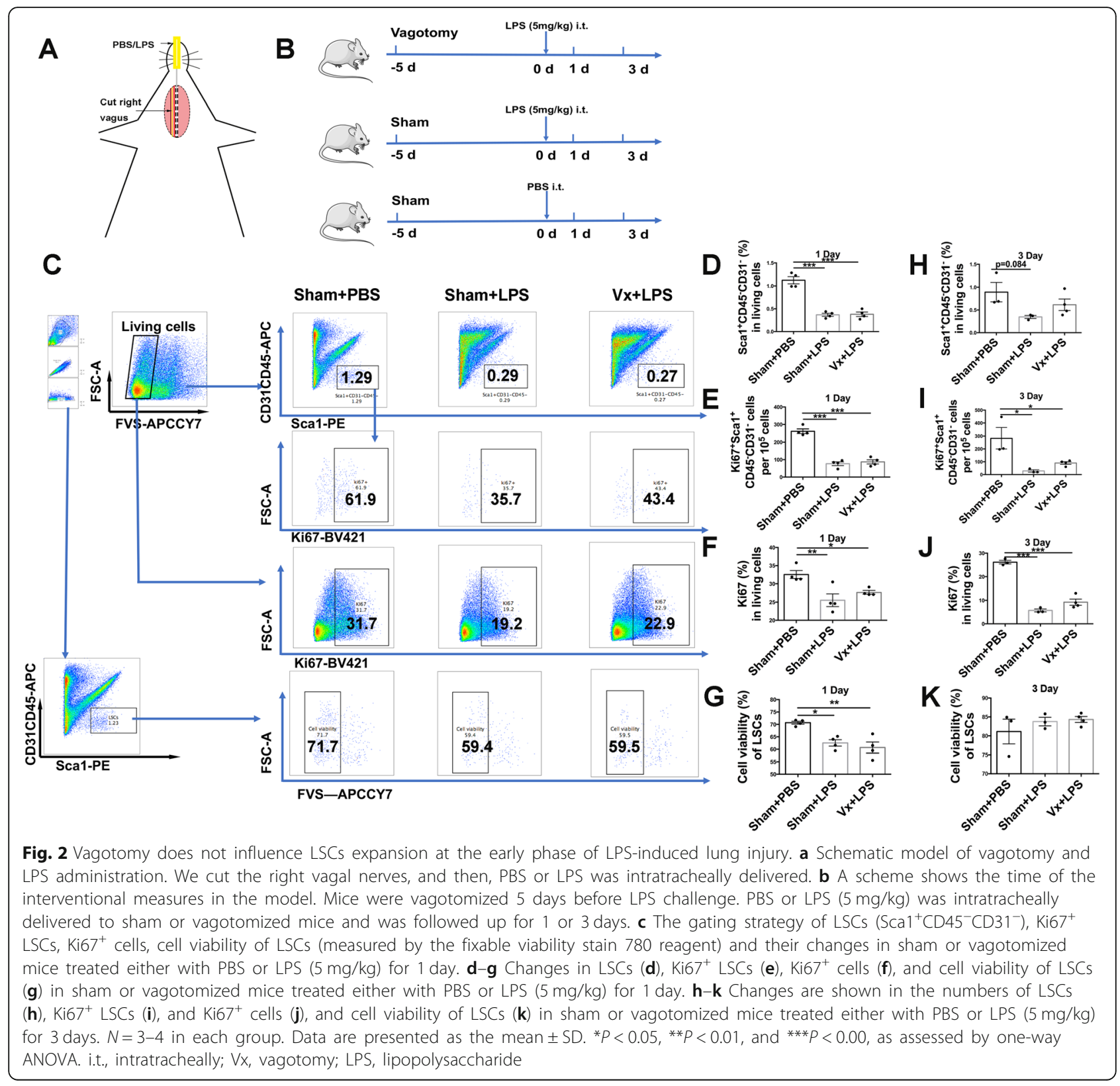

inhibited $\mathrm{Ki}^{+} 7^{+}$LSCs without changing the cell viability of LSCs on the 7 th day after LPS $(2.5 \mathrm{mg} / \mathrm{kg})$ challenge. However, activation of $\alpha 7 \mathrm{nAChR}$ significantly resulted in the expansion of Ki67 ${ }^{+}$cells, LSCs, and Ki67 ${ }^{+}$LSCs (Fig. 4e-h), indicating that the vagus nerve promotes LSCs proliferation and enhances the reparative process via $\alpha 7 \mathrm{nAChR}$ rather than through improving cell survival. Considering that FGF10 was found to promote the proliferation and transdifferentiation of LSCs with in vitro study, we speculated that the protective effect of vagal- $\alpha 7 n A C h R$ signaling was FGF10 dependent. We found that vagotomy decreased the expression of FGF10 protein in the distal lung mesenchyme (Fig. 5a, b) and reduced FGF10 mRNA expression in the total lungs (Fig. 5c), which was accompanied by the loss of SP-C $\mathrm{C}^{+}$cells (Fig. 5d, e) and reduction of SP-C mRNA (Fig. $5 \mathrm{f})$ on the 7th day post LPS challenge. Activation of $\alpha 7 n A C h R$ prevented the downregulation of FGF10 and accelerated SP-C $\mathrm{C}^{+}$cells repopulation in vagotomized mice at the reparative phase of LPS-induced lung injury (Fig. 5a-f). Collectively, these data supported the idea that the vagus nerve, via $\alpha 7 \mathrm{nAChR}$, promoted FGF10 expression in the distal lung mesenchyme, which then facilitated LSCs proliferation and transdifferentiation into AEC2. The LSCs expansion induced by $\alpha 7 \mathrm{nAChR}$ activation may be explained by enhanced proliferation prevailing over the transdifferentiation process. 


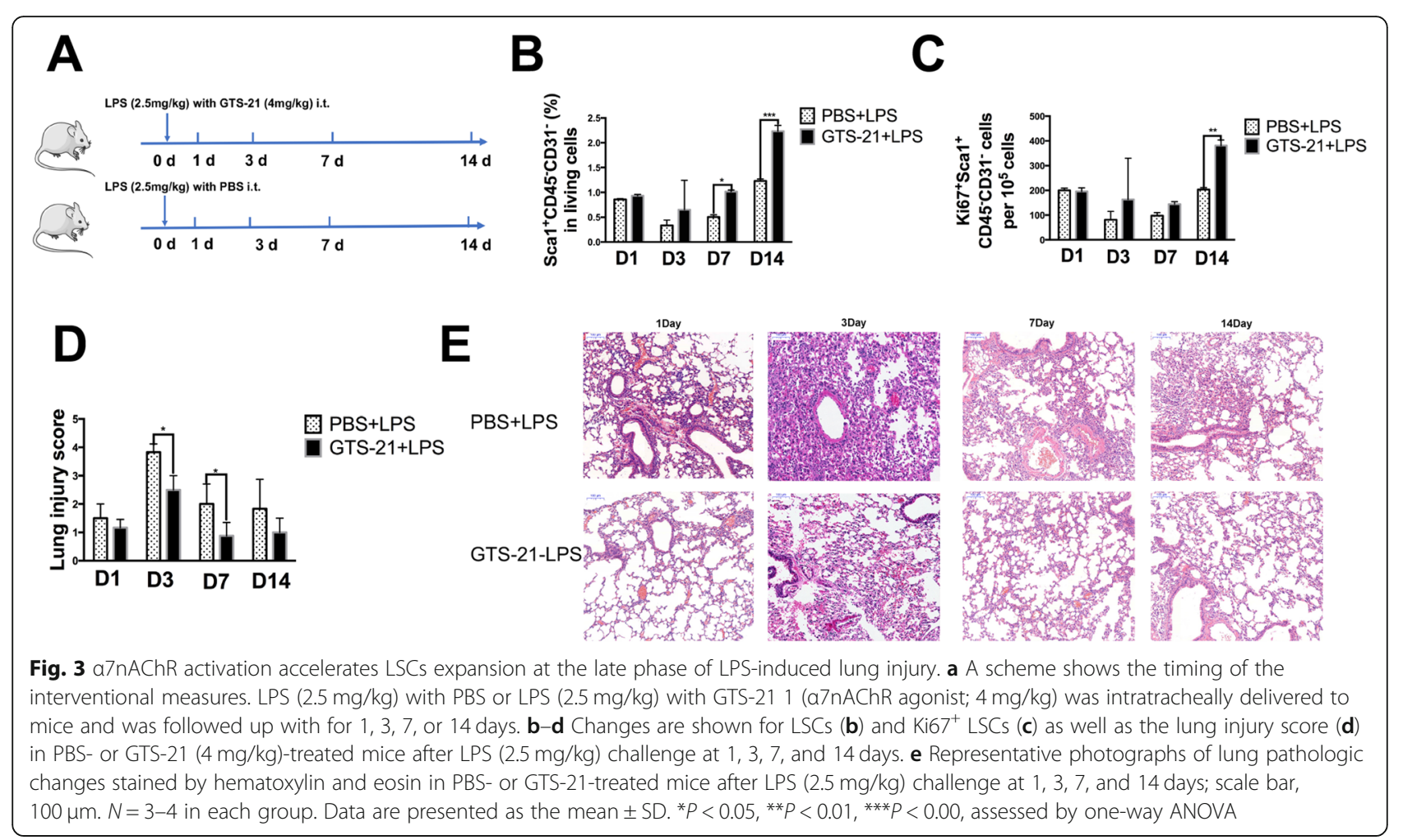

FGF10 reverses a7nAChR knockout-induced loss of Ki67 ${ }^{+}$ LSCs and reduction of AEC2

The aforementioned findings indicate that activation of $\alpha 7 \mathrm{nAChR}$ induces LSCs proliferation and transdifferentiation with activation of the FGF10 pathway engaging with vagal signals. To further confirm whether FGF10 plays an important role in this process, we used $\alpha 7 \mathrm{nAChR}$ knockout mice and designed an FGF10 rescue assay (Fig. 6a). We found that FGF10 administration partially reversed the $\alpha 7 \mathrm{nAChR}$ deletion-induced deteriorated lung damage (Fig. 6b, c). Furthermore, $\alpha 7 \mathrm{nAChR}$ ablation resulted in a significant loss of $\mathrm{Ki}^{+} 7^{+}$cells (Fig. 6d) and $\mathrm{Ki}^{+} 7^{+} \mathrm{LSCs}$ (Fig. 6e) and a downward trend of the number of LSCs (Fig. 6f) over 7-day period after LPS challenge. Importantly, $\alpha 7 \mathrm{nAChR}$ deletion-induced $\mathrm{Ki}^{+} 7^{+} \mathrm{LSCs}$ loss was significantly rescued by FGF10. FGF10 protein and mRNA levels were decreased in $\alpha 7 \mathrm{nAChR}$ knockout mice (Fig. 7a-c), suggesting that activation of $\alpha 7 \mathrm{nAChR}$ promotes LSCs proliferation and transdifferentiation via the FGF10 pathway. In addition, LPS-challenged $\alpha 7 n A C h R$ knockout lungs exhibited a decreased number of AEC2 labeled by SP-C (Fig. 7df). FGF10 reversed $\alpha 7 \mathrm{nAChR}$ knockout-induced loss of AEC2. These data supported the concept that LSCs deploy $\alpha 7 \mathrm{nAChR}-\mathrm{FGF} 10$ signaling to control their fate including proliferation and transdifferentiation.

\section{Discussion}

The adult lung is a quiescent tissue under normal physiologic conditions, but it responds efficiently to injury by activating the proliferation and transdifferentiation of stem/progenitor cells to reconstitute the alveolar epithelium and promote recovery [33]. However, whether this regenerative process leads to normal or dysplastic repair is dependent on several factors, and we herein provide additional insights into this process. We clarified that the vagus nerve via $\alpha 7 \mathrm{nAChR}$ leads to LSCs proliferation and transdifferentiation and accelerates the reparative process after lung injury. LSCs proliferation and transdifferentiation during the reparative process of LPS-induced lung injury consists of transmission of the vagus nerve, lung $\alpha 7 \mathrm{nAChR}$ activation, and FGF10-dependent improved proliferation and transdifferentiation in LSCs. Moreover, vagal- $\alpha 7 \mathrm{nAChR}$ signaling was proven to be an activator of the FGF10 pathway. Thus, based on the present findings, we conclude that vagal- $\alpha 7 \mathrm{nAChR}$ signaling regulates LSCs in an FGF10dependent manner, which leads to lung stem cells proliferation and transdifferentiation after lung injury.

Depending on the type and severity of lung injury, different cell types are involved in the reparative process after lung injury [33-35]. It has been reported in previous investigations that vagal- $\alpha 7 \mathrm{nAChR}$ signaling protects against various acute lung injuries [13, 17, 18]. To 


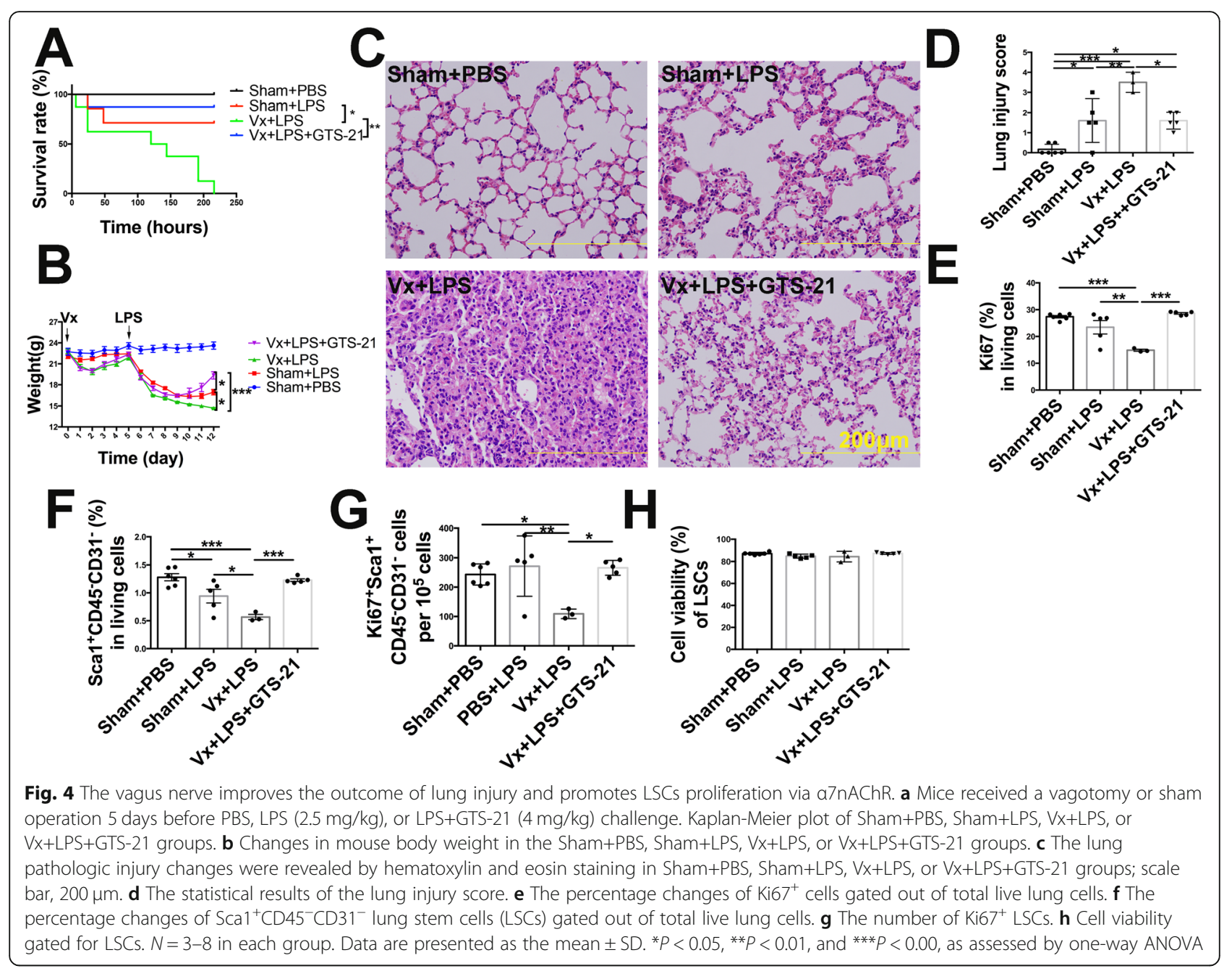

address whether this signaling affects stem cell-mediated lung repair, we comprehensively examined the changes in lung stem cell markers in LPS-challenged vagotomized mice or $\alpha 7 \mathrm{nAChR}-\mathrm{knockout}$ mice. We found that the number of lung stem cells in $\mathrm{Sca} 1^{+} \mathrm{CD} 45^{-} \mathrm{CD} 31^{-}$ populations of cells was reduced after LPS-induced lung injury, and an obvious expansion of potentially regenerative Sca $1^{+} \mathrm{CD} 45^{-} \mathrm{CD} 31^{-}$cells was observed in the mouse lung 1 to 2 weeks after LPS challenge. In addition, administration of an $\alpha 7 \mathrm{nAChR}$ agonist (GTS-21) accelerated the proliferation and expansion of $\mathrm{Sca} 1^{+} \mathrm{CD} 45^{-} \mathrm{CD} 31^{-}$cells during the reparative process after LPS-induced lung injury.

Sca $1^{+} \mathrm{CD} 45^{-} \mathrm{CD} 31^{-}$cells were originally identified as BASCs [1]. However, some studies demonstrated that $\mathrm{Sca} 1^{+} \mathrm{CD} 45^{-} \mathrm{CD} 31^{-}$cells comprise a heterogeneous population of progenitors, which are mainly lung mesenchymal progenitors $[5,10]$ or a population of multipotent stem cells [6]. The divergence concerning the phenotype of Sca $1^{+} \mathrm{CD} 45^{-} \mathrm{CD} 31^{-}$cells was explained by different antibodies obtained from different companies that showed variability in the cell populations isolated according to these markers. We similarly assessed this cell population after isolation. Consistent with Hegab' study [6], we observed that LSCs possessed self-renewal capacity and possessed the characteristics of mesenchymal stem cells and lung epithelial stem cells. Hence, $\mathrm{Sca} 1^{+} \mathrm{CD} 45^{-} \mathrm{CD} 31^{-}$cells are bona fide lung stem cells and can be used to assess the lung regeneration and reparative processes. Importantly, we found that vagotomy increased mortality, delayed body weight recovery, and exacerbated lung pathological damage in LPS-induced lung injury mouse models. The application of an $\alpha 7 \mathrm{nAChR}$ agonist reversed the vagotomyinduced high mortality, body weight loss, and lung injury. Furthermore, vagotomy led to LSCs loss by inhibiting their proliferation and reduced the number of SP-C $\mathrm{C}^{+}$cells, but this effect could be rescued by GTS-21 administration. These data support the idea that vagal- $\alpha 7 \mathrm{nAChR}$ signaling regulates the proliferation of LSCs and promotes the regenerative process after injury.

Several lines of evidence have highlighted the importance of FGF10 in lung regeneration regulation. FGF10 


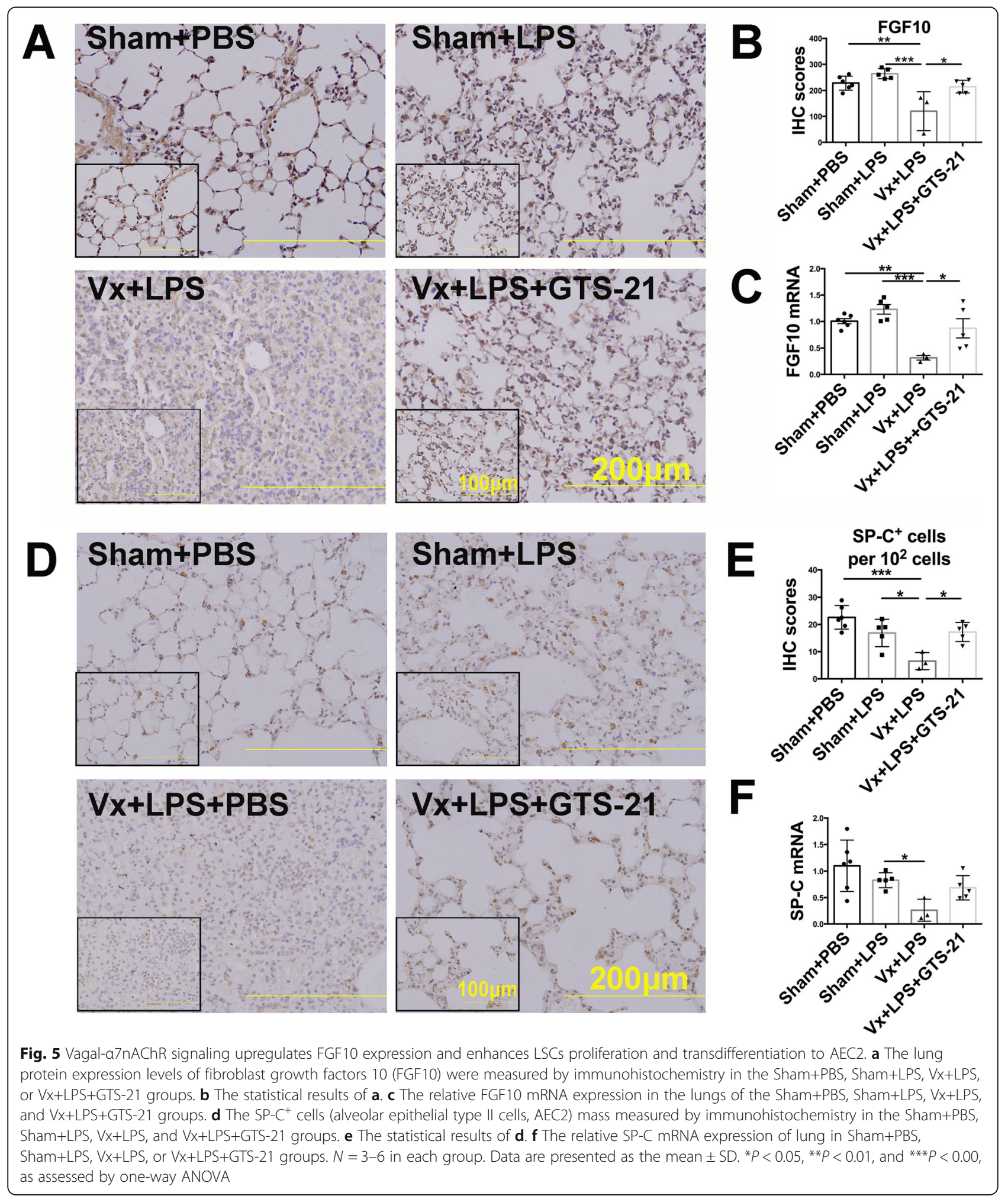

overexpression has been reported to enable basal stem cells to repopulate the noncartilaginous airways [36]. Moreover, FGF10-FGFR2B signaling promoted the expansion of basal cells and alveolar epithelial regeneration after lung injury [37]. In this study, we observed that vagotomy decreased the expression of FGF10 in the distal lung mesenchyme, which was accompanied by the loss of $\mathrm{SP}_{-} \mathrm{C}^{+}$cells at the reparative phase after LPS 


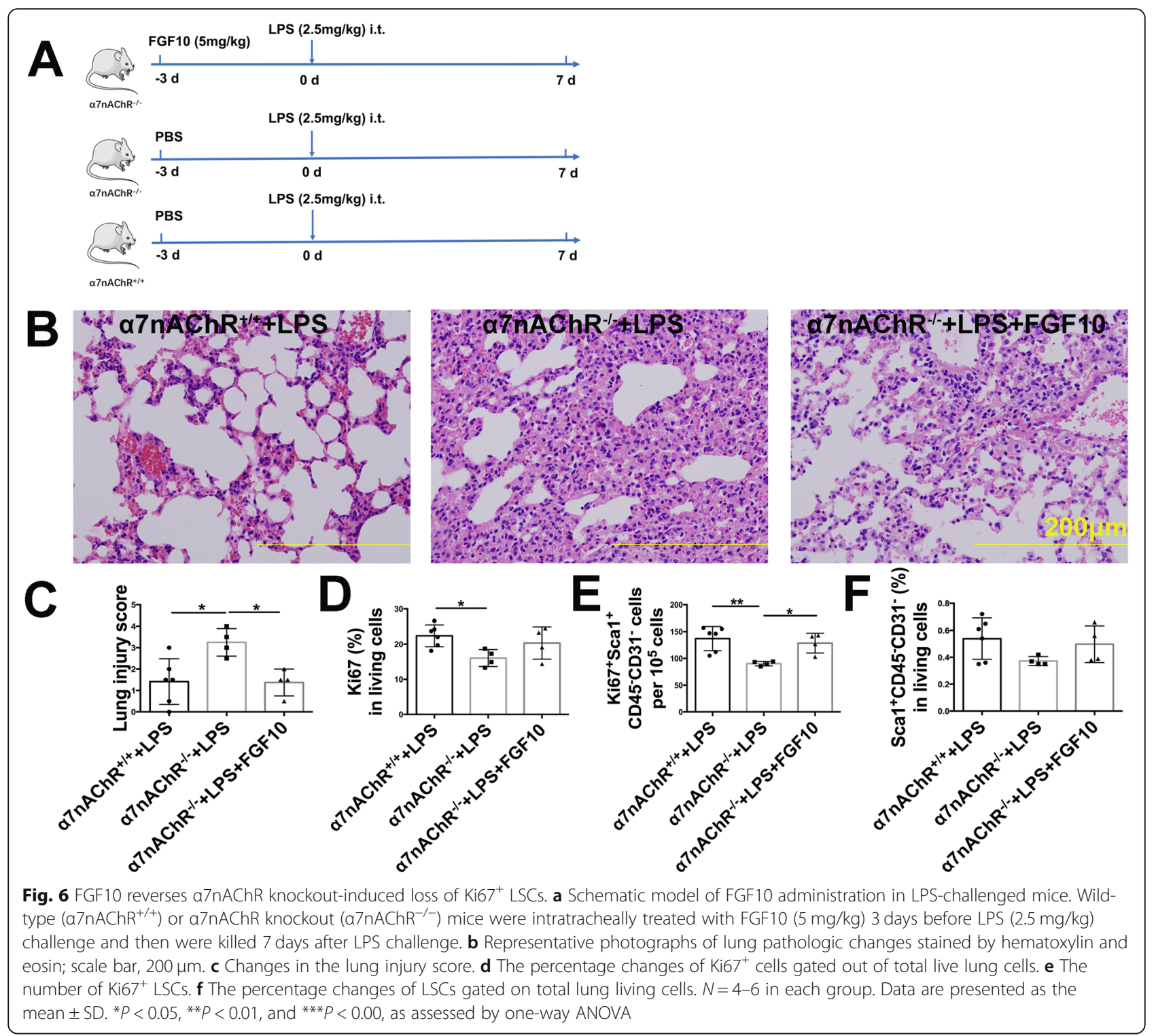

challenge. Activation of $\alpha 7 \mathrm{nAChR}$ could prevent the downregulation of FGF10 and the loss of SP-C ${ }^{+}$cells. Supplementation with FGF10 could prevent $\alpha 7 \mathrm{nAChR}$ knockout-induced lung injury and $\alpha 7 \mathrm{nAChR}$ knockoutinduced the loss of $\mathrm{Ki}^{+} 7^{+} \mathrm{LSCs}$ and SP-C ${ }^{+}$cells during LPS-induced lung injury. Previously, we also demonstrated that $\alpha 7 \mathrm{nAChR}$ deficiency could increase proinflammatory cytokines in lung injury caused by LPS challenge $[17,18]$ and that FGF-10 could mobilize mesenchymal stem cells and reduce lung inflammatory cytokines [38]. In addition, it has been reported that FGF10 is also expressed on a population of lipofibroblasts that are spatially associated with AEC2 cells [39]. These findings are consistent with FGF10 immunofluorescent staining in this study. Collectively, these data indicate that vagal- $\alpha 7 \mathrm{nAChR}$ signaling enhances FGF10 expression in the lung mesenchyme and that FGF10 in turn promotes LSCs proliferation and transdifferentiation to AEC2. In addition, we also confirmed that FGF10 promotes LSCs proliferation and transdifferentiation in vitro in our study. Meanwhile, vagus nerve-induced proliferation prevails over transdifferentiation during the expansion of LSCs.

Retardation of regeneration in both the liver [40] and pancreatic islet [24] and impairment of extremity regeneration $[41,42]$ due to surgical denervation have been widely observed. Support for the idea that tissue regeneration is governed by neuronal signaling has been demonstrated for a few decades. However, the exact mechanisms remain unknown. This is the first study that clarifies the positive effect of vagal- $\alpha 7 \mathrm{nAChR}$ signaling at the reparative phase after lung injury. We found that the vagus nerve, via $\alpha 7 \mathrm{nAChR}$, promotes lung stem cell 


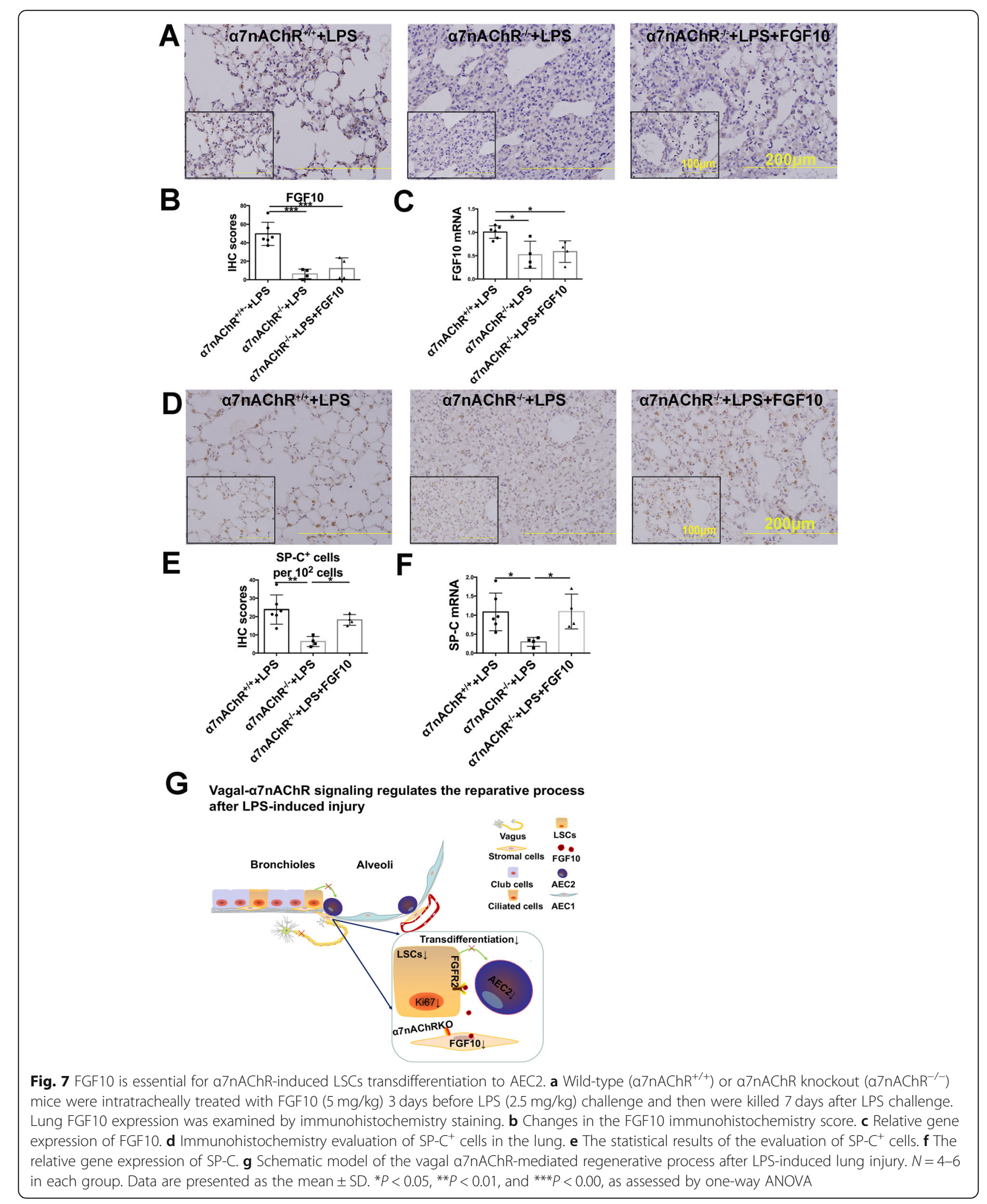


proliferation and expansion in an FGF10-dependent manner. Thus, vagus stimulation and $\alpha 7 \mathrm{nAChR}$ agonist might be potent therapeutic targets for treating lung injury. The concept of vagal- $\alpha 7 \mathrm{nAChR}$ signaling governing lung stem cell proliferation may open a new avenue of research in the field of lung regeneration.

\section{Conclusion}

Vagal- $\alpha 7 n A C h R$ signaling promotes lung stem cell $\left(\mathrm{Sca1}^{+} \mathrm{CD} 45^{-} \mathrm{CD} 31^{-}\right)$expansion and accelerates the reparative process of lung injury, and this process is FGF10 dependent. Vagus nerve $\alpha 7 \mathrm{nAChR}$-mediated lung injury repair holds potential for the development of novel approaches to lung stem cell therapy. A schematic image showing that vagal- $\alpha 7 \mathrm{nAChR}$ signaling regulates the reparative process after lung injury is showed in Fig. $7 \mathrm{~g}$.

\section{Supplementary information}

Supplementary information accompanies this paper at https://doi.org/10. 1186/s13287-020-01757-w.

Additional file 1: Figure S1. LSCs possess self-renewal ability. A. In the LDA assay, we observed that $25.61 \% \pm 5.79 \%$ of the wells contained colonies. In addition, seeding of single cells that originated from secondary clones could generate tertiary clones, further confirming their selfrenewal ability. Daughter colonies were always morphologically identical to primary cell colonies. Clones could be cryopreserved. And when recultured, their growth kinetics or morphology were not changed. B. When treated with FGF10, LSCs elongated and aligned themselves end to end in alveolar-like shapes within 2-3 days.

\section{Abbreviations}

LSCs: Lung stem cells; Sca1: Stem cell antigen 1; a7nAChR: Alpha7 nicotinic acetylcholine receptor; LPS: Lipopolysaccharide; FGF10: Fibroblast growth factor 10; RT-PCR: Real-time polymerase chain reaction; AEC1: Alveolar epithelial type I cells; AEC2: Alveolar epithelial type II cells; ARDS: Acute respiratory distress syndrome; FGFs: Fibroblast growth factors;

FGFR2: Fibroblast growth factor receptor 2; PE: Phycoerythrin; Cy3: Cyanine 3 (Cy3); FVS780: Fixable viability stain 780; APC: Allophycocyanin;

FITC: Fluorescein isothiocyanate; Vx: Vagotomy; PBS: Phosphate buffer saline; SP-C: Surfactant protein C; CCSP: Club-cell specific protein;

AQP5: Aquoporin5; a-SMA: Alpha smooth muscle actin; SD: Standard deviation

\section{Acknowledgements}

The authors gratefully acknowledge all members of the Yuanlin Song laboratory and Xiao Su laboratory and Dr. Yaohui Li for their help.

\section{Authors' contributions}

$X C$ designed and performed the experiments and wrote the manuscript. $C$ Zhao performed the experiments and analyzed the data. C Zhang performed the experiments and revised the manuscript. $\mathrm{QL}$ performed the flow cytometry and prepared the histology sample. JC performed the vagotomies. LC performed the gene identification of mice. JZ provided the reagents/ materials and revised the manuscript. XS and YS conceived, designed, and revised the experiments. All authors read and approved the final manuscript.

\section{Funding}

This study was supported by the National Natural Science Foundation of China key grant $(81630001,81490533)$, grant $(81730001,91942305,81970075$, 81570028, 81770039, 81800077), the Strategic Leading Project (B) of CAS (XDPB0303), the National Major Scientific and Technological Special Project for "Significant New Drugs Development" (2018ZX09201002-006), the
International Collaboration project of CAS (153831KYSB20170043), and the Shanghai Education Commission High Level Innovation Team Incentive Plan.

Availability of data and materials

All data generated or analyzed during this study are included in this published article.

\section{Ethics approval and consent to participate}

The protocols were approved by the Committees on Animal Research of the Institut Pasteur of Shanghai, Chinese Academy of Sciences, China.

\section{Consent for publication}

Not applicable.

\section{Competing interests}

The authors declare that they have no competing interests

\section{Author details}

${ }^{1}$ Department of Pulmonary and Critical Care Medicine, Zhongshan Hospital, Fudan University and Shanghai Respiratory Research Institute, 180 Fenglin Road, Shanghai 200032, People's Republic of China. ${ }^{2}$ Unit of Respiratory Infection and Immunity, Institut Pasteur of Shanghai, Chinese Academy of Sciences, 320 Yueyang Road, Shanghai 200031, People's Republic of China. ${ }^{3}$ Department of Pulmonary Medicine, Zhongshan Hospital, Qingpu Branch, Fudan University, Shanghai, People's Republic of China. ${ }^{4}$ National Clinical Research Center for Aging and Medicine, Huashan Hospital, Fudan University, Shanghai, People's Republic of China.

Received: 18 April 2020 Revised: 19 May 2020

Accepted: 1 June 2020 Published online: 10 June 2020

\section{References}

1. Kim CF, Jackson EL, Woolfenden AE, Lawrence S, Babar I, Vogel S, et al. Identification of bronchioalveolar stem cells in normal lung and lung cancer. Cell. 2005;121(6):823-35.

2. Thomas PG, Quantius J, Schmoldt C, Vazquez-Armendariz Al, Becker C, El Agha E, et al. Influenza virus infects epithelial stem/progenitor cells of the distal lung: impact on Fgfr2b-driven epithelial repair. PLOS Pathogens. 2016; 12(6):e1005544.

3. Liu Q, Liu K, Cui G, Huang X, Yao S, Guo W, et al. Lung regeneration by multipotent stem cells residing at the bronchioalveolar-duct junction. Nat Genet. 2019;51(4):728-38.

4. Kotton DN, Morrisey EE. Lung regeneration: mechanisms, applications and emerging stem cell populations. Nat Med. 2014;20(8):822-32.

5. McQualter JL, Brouard N, Williams B, Baird BN, Sims-Lucas S, Yuen K, et al. Endogenous fibroblastic progenitor cells in the adult mouse lung are highly enriched in the sca-1 positive cell fraction. Stem Cells. 2009:27(3):623-33.

6. Hegab AE, Kubo H, Fujino N, Suzuki T, He M, Kato H, et al. Isolation and characterization of murine multipotent lung stem cells. Stem Cells Dev. 2010;19(4):523-36

7. Curtis SJ, Sinkevicius KW, Li D, Lau AN, Roach RR, Zamponi R, et al. Primary tumor genotype is an important determinant in identification of lung cancer propagating cells. Cell Stem Cell. 2010;7(1):127-33.

8. Abler LL, Mansour SL, Sun X. Conditional gene inactivation reveals roles for Fgf10 and Fgfr2 in establishing a normal pattern of epithelial branching in the mouse lung. Dev Dyn. 2009;238(8):1999-2013.

9. Volckaert T, De Langhe SP. Wnt and FGF mediated epithelial-mesenchymal crosstalk during lung development. Dev Dyn. 2015:244(3):342-66.

10. McQualter JL, Yuen K, Williams B, Bertoncello I. Evidence of an epithelial stem/progenitor cell hierarchy in the adult mouse lung. Proc Natl Acad Sci U S A. 2010;107(4):1414-9.

11. Volckaert T, De Langhe S. Lung epithelial stem cells and their niches: Fgf10 takes center stage. Fibrogenesis Tissue Repair. 2014;7(8). https://doi.org/10. 1186/1755-1536-7-8.

12. El Agha E, Herold S, Al Alam D, Quantius J, MacKenzie B, Carraro G, et al. Fgf10-positive cells represent a progenitor cell population during lung development and postnatally. Development. 2014;141(2):296-306.

13. Su X, Lee JW, Matthay ZA, Mednick G, Uchida T, Fang X, et al. Activation of the alpha7 nAChR reduces acid-induced acute lung injury in mice and rats. Am J Respir Cell Mol Biol. 2007;37(2):186-92. 
14. Fox BBT, Guz A. Innervation of alveolar walls in the human lung: an electron microscopic study. J Anat. 1980;131:10.

15. Bando H, Nishio T, van der Horst GTJ, Masubuchi S, Hisa Y, Okamura H. Vagal regulation of respiratory clocks in mice. J Neurosci. 2007;27(16):4359-65.

16. Tracey KJ. Reflex control of immunity. Nat Rev Immunol. 2009;9(6):418-28.

17. Zhao C, Yang X, Su EM, Huang Y, Li L, Matthay MA, et al. Signals of vagal circuits engaging with AKT1 in alpha7 nAChR(+)CD11b(+) cells lessen E. coli and LPS-induced acute inflammatory injury. Cell Discovery. 2017:3:17009.

18. Su X, Matthay MA, Malik AB. Requisite role of the cholinergic alpha7 nicotinic acetylcholine receptor pathway in suppressing Gram-negative sepsis-induced acute lung inflammatory injury. J Immunol. 2010;184(1):401-10.

19. Sitapara RA, Antoine DJ, Sharma L, Patel VS, Ashby CR Jr, Gorasiya S, et al. The alpha7 nicotinic acetylcholine receptor agonist GTS-21 improves bacterial clearance in mice by restoring hyperoxia-compromised macrophage function. Mol Med. 2014;20:238-47.

20. Wang J, Li R, Peng Z, Zhou W, Hu B, Rao X, et al. GTS-21 reduces inflammation in acute lung injury by regulating $M 1$ polarization and function of alveolar macrophages. Shock. 2019;51(3):389-400.

21. Mei Z, Tian X, Chen J, Wang Y, Yao Y, Li X, et al. alpha7nAchR agonist GTS21 reduces radiationinduced lung injury. Oncol Rep. 2018;40(4):2287-97.

22. Giebelen IA, van Westerloo DJ, LaRosa GJ, de Vos AF, van der Poll T. Local stimulation of alpha7 cholinergic receptors inhibits LPS-induced TNF-alpha release in the mouse lung. Shock. 2007;28(6):700-3.

23. Khan MA, Farkhondeh M, Crombie J, Jacobson L, Kaneki M, Martyn JA. Lipopolysaccharide upregulates alpha7 acetylcholine receptors: stimulation with GTS-21 mitigates growth arrest of macrophages and improves survival in burned mice. Shock. 2012;38(2):213-9.

24. Yamamoto J, Imai J, Izumi T, Takahashi H, Kawana Y, Takahashi K, et al. Neuronal signals regulate obesity induced beta-cell proliferation by FoxM1 dependent mechanism. Nat Commun. 2017;8(1):1930.

25. Garcia-Garcia A, Korn C, Garcia-Fernandez M, Domingues O, Villadiego J, Martin-Perez D, et al. Dual cholinergic signals regulate daily migration of hematopoietic stem cells and leukocytes. Blood. 2019;133(3):224-36.

26. Pierce H, Zhang D, Magnon C, Lucas D, Christin JR, Huggins M, et al. Cholinergic signals from the CNS regulate G-CSF-mediated HSC mobilization from bone marrow via a glucocorticoid signaling relay. Cell Stem Cell. 2017;20(5):648-58.

27. Serobyan N, Jagannathan S, Orlovskaya I, Schraufstatter I, Skok M, Loring J, et al. The cholinergic system is involved in regulation of the development of the hematopoietic system. Life Sci. 2007;80(24-25):2352-60.

28. Huang Y, Zhao C, Chen J, Su X. Deficiency of HIF-1alpha in myeloid cells protects E. coli or LPS-induced acute lung injury. QJM : Monthly Journal of the Association of Physicians. 2018;111(10):707-14.

29. Song Y, Baer M, Srinivasan R, Lima J, Yarranton G, Bebbington C, et al. PcrV antibody-antibiotic combination improves survival in Pseudomonas aeruginosa-infected mice. Eur J Clin Microbiol Infect Dis. 2012;31(8):1837-45.

30. Zhang L, Yu H, Badzio A, Boyle TA, Schildhaus H-U, Lu X, et al. Fibroblast growth factor receptor 1 and related ligands in small-cell lung cancer. J Thorac Oncol. 2015;10(7):1083-90.

31. Livak KJ, Schmittgen TD. Analysis of relative gene expression data using real-time quantitative $P C R$ and the $2-\Delta \Delta C T$ method. Methods. 2001;25(4): 402-8.

32. Gerdes J, Lemke H, Baisch H, Wacker HH, Schwab U, Stein H. Cell cycle analysis of a cell proliferation-associated human nuclear antigen defined by the monoclonal antibody Ki-67. J Immunol. 1984;133(4):1710-5.

33. Desai TJ, Brownfield DG, Krasnow MA. Alveolar progenitor and stem cells in lung development, renewal and cancer. Nature. 2014;507(7491):190-4.

34. Vaughan AE, Brumwell AN, Xi Y, Gotts JE, Brownfield DG, Treutlein B, et al. Lineage-negative progenitors mobilize to regenerate lung epithelium after major injury. Nature. 2015;517(7536):621-5.

35. Xi Y, Kim T, Brumwell AN, Driver IH, Wei Y, Tan V, et al. Local lung hypoxia determines epithelial fate decisions during alveolar regeneration. Nat Cell Biol. 2017;19(8):904-14.

36. Volckaert T, Yuan T, Chao C-M, Bell H, Sitaula A, Szimmtenings L, et al. Fgf10-Hippo epithelial-mesenchymal crosstalk maintains and recruits lung basal stem cells. Developmental Cell. 2017;43(1):48-59 e5.

37. Yuan T, Volckaert T, Redente EF, Hopkins S, Klinkhammer K, Wasnick R, et al. FGF10-FGFR2B signaling generates basal cells and drives alveolar epithelial regeneration by bronchial epithelial stem cells after lung injury. Stem Cell Reports. 2019;12(5):1041-55.
38. Tong L, Zhou J, Rong L, Seeley EJ, Pan J, Zhu X, et al. Fibroblast growth factor-10 (FGF-10) mobilizes lung-resident mesenchymal stem cells and protects against acute lung injury. Sci Rep. 2016;6:21642.

39. Barkauskas CE, Cronce MJ, Rackley CR, Bowie EJ, Keene DR, Stripp BR, et al. Type 2 alveolar cells are stem cells in adult lung. J Clin Invest. 2013;123(7): 3025-36.

40. Kato H, Shimazu T. Effect of autonomic denervation on DNA synthesis during liver regeneration after partial hepatectomy. Eur J Biochem. 1983; 134(3):473-8.

41. Lebowitz $P$, Singer M. Neurotrophic control of protein synthesis in the regenerating limb of the newt. Triturus Nature. 1970;225(5235):824-7.

42. Singer $M$. The influence of the nerve in regeneration of the amphibian extremity. Q Rev Biol. 1952;27(2):169-200.

\section{Publisher's Note}

Springer Nature remains neutral with regard to jurisdictional claims in published maps and institutional affiliations.
Ready to submit your research? Choose BMC and benefit from:

- fast, convenient online submission

- thorough peer review by experienced researchers in your field

- rapid publication on acceptance

- support for research data, including large and complex data types

- gold Open Access which fosters wider collaboration and increased citations

- maximum visibility for your research: over $100 \mathrm{M}$ website views per year

At $\mathrm{BMC}$, research is always in progress.

Learn more biomedcentral.com/submissions 